\title{
A generalized concentration curve (GCC) method for storm flow hydrograph prediction in a conceptual linear reservoir-channel cascade
}

\author{
Hui Wan, Jun Xia, Liping Zhang, Wenhua Zhang, Yang Xiao, Christopher \\ J. Gippel, Dunxian She and Chongyu Xu
}

\begin{abstract}
The unit hydrograph $(\mathrm{UH})$ is a hydrological tool that represents the unit response of a watershed to a unit input of rainfall. UH models based on lumped reservoir and channel conceptual cascade assume that rainfall is evenly distributed, thus limiting the use of UHs to relatively small watersheds of less than around $500 \mathrm{~km}^{2}$ in area. In this paper, a new hydrograph prediction method, named the generalized concentration curve (GCC), was derived that can be applied to large heterogeneous watersheds. The GCC method divides the watershed into subareas by isochrones. In each subarea, an independent linear reservoir-channel cascade model that considers both attenuation and translation is established. Comparative application of the GCC and the traditional Nash instantaneous unit hydrograph to 18 storm events from three medium-sized watersheds $(727,1,800$ and 5,253 km² in area) revealed superior performance of the GCC, with the average Nash-Sutcliffe efficiency coefficient higher by $7.66 \%$, and the average peak discharge error lower by $4.14 \%$. This study advances the theory of UH and expands the scope of application of UH to larger watersheds.
\end{abstract} Key words | isochronal method, storage, surface runoff, translation, unit hydrograph

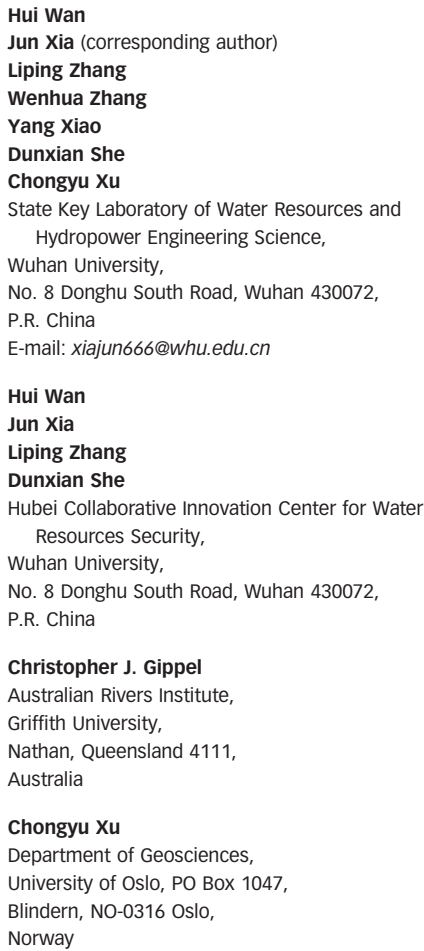

\section{INTRODUCTION}

Predicting storm runoff magnitude, timing and recurrence interval is one of the most common practical tasks undertaken by hydrologists. The two main approaches to modelling the translation of effective rainfall inputs to storm flow outputs are data-driven, both empirical blackbox and conceptual model types, and knowledge-driven distributed physically-meaningful model types (Todini 2007). A basic foundation of the data-driven approach is the unit hydrograph (UH), a lumped, linear conceptual model that describes storm runoff over time at a point resulting from one unit of effective rainfall distributed uniformly over a watershed at a uniform rate during a unit period of time (Dooge 1973). Since it was first introduced by Sherman (1932), the UH concept has been widely used in rainfallrunoff models to predict total event runoff and flood peak magnitude. A range of non-parametric and parametric methods has been used to evaluate the UH (Yang \& Han 2006). This paper is concerned only with the parametric approach, in particular, models of hydrographs having a limited number of parameters (usually two or three) that are widely applied to the problem of predicting storm flow hydrographs in ungauged or poorly gauged watersheds. 
The development and contribution of the UH concept to the field of storm flow runoff prediction has a long and rich history (e.g. Dooge 1973; Sheridan 1994; Ramirez 2000; Todini 2007). After conceptualizing a watershed simply as $n$ linearly arranged contributing subareas (Figure 1), Ross (I92I) introduced the importance of watershed characteristics to the transfer process through the concept known as isochrones. These are lines of equal time for runoff to reach the watershed outlet, which can be graphed as a time-area (TA) curve. The time-area-concentration (TAC) curve is the derivative of the TA curve, with its base length equals to the time of concentration, or the length of time for a parcel of runoff to travel from the most remote part of a watershed to the location of interest, such as the outlet (Dooge 1973). Considering only translation without attenuation of flow over the ground would tend to overestimate the peak rate of discharge, so most UH models conceptualize the watershed as a linear system of reservoirs, or storages, that attenuate the flow, between which flow is translated through channels (Dooge 1973; Singh 1990). The

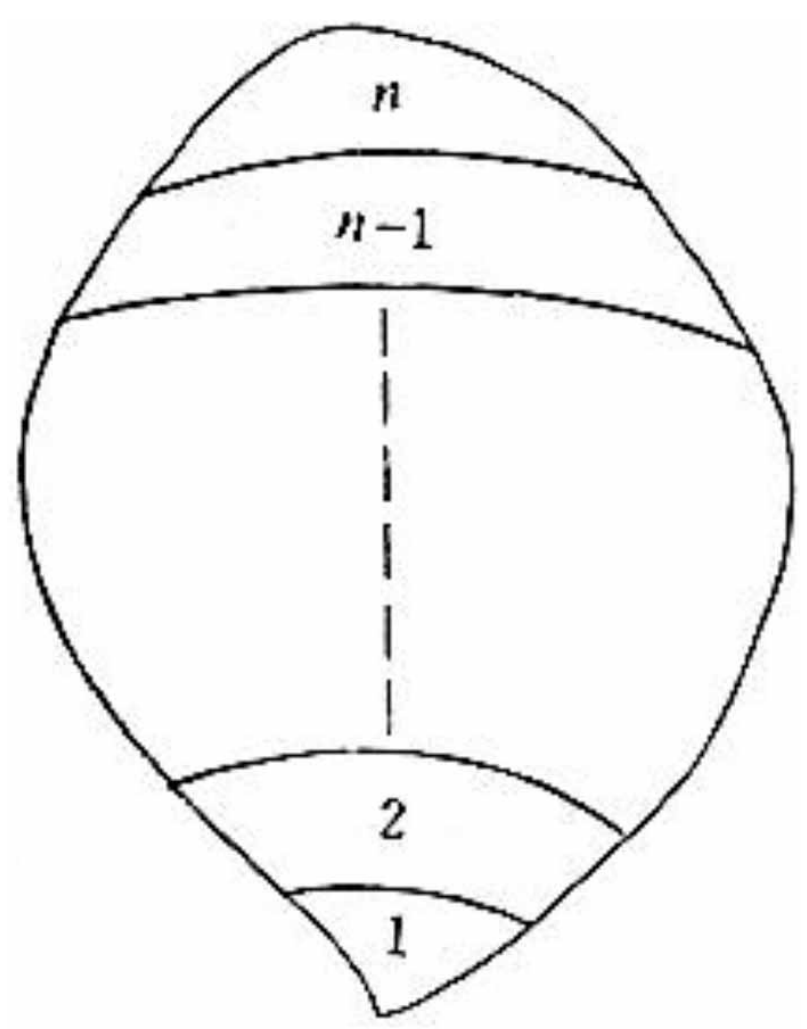

Figure 1 | Conceptual watershed separated into contributing sub-areas. first such model, developed by Zoch (1934, 1936, 1937), consisted of a single linear reservoir (Figure 2), solved for the cases of a rectangular- and a triangular-shaped TAC curve. The TAC formulation of Zoch was simplified by Clark (I945) by assuming that the input rainfall would occur at a very short period to obtain the instantaneous unit hydrograph (IUH). Clark's (I945) model used the Muskingum equation for routing, and relied on empirical data to determine the storage discharge constant $(K)$ and time of concentration $\left(T_{c}\right)$. O'Kelly (1955) replaced the curvilinear TAC curve with an isosceles triangle and routed it through a linear reservoir. Nash (1957) developed a runoff function, often referred to as the 'gamma distribution,' that was destined to become one of the most widely used models in applied hydrology (Ramirez 200o). While Clark (I945) routed the unit runoff impulse in the form of a TAC, Nash (1957) represented the watershed with a cascade of equal linear reservoirs (Figure 2), with the physical characteristics of the watershed described by two parameters, $n$, the number of linear reservoirs (which could take non-integral values), and $K$, reservoir storage coefficient. Dooge (1957) criticized Nash's elimination of the translation element, and found his assumption that the linked reservoirs were identical to be unattractive from a physical viewpoint. He separated the reservoirs by a series of channels (Figure 2) and then, on the assumption that the order of reservoirs and channels was immaterial, conceptually lumped the $n$ channels into a single element positioned upstream of the reservoirs (Dooge 1959) (Figure 2). A hybrid UH model was then developed with the effective rainfall passing through the channel and reservoirs from the watershed source. In practice, the reservoirs were assumed identical and the form of the UH was simplified by integrating the product of the TAC curve and the Poisson probability function (Dooge 1959). At around the same time, Kalinin \& Milyukov (1957) independently applied the same cascade concept to flood routing. In a separate development, the relation between hydrological response and watershed geomorphometry, represented by stream order, was used to develop the geomorphological instantaneous unit hydrograph (Rodriguez-Iturbe \& Valdés 1979). More recently, Singh (20II) derived a general equation for IUH using entropy theory that specialized into several well-known IUH equations, including Nash's gamma distribution. 


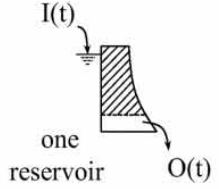

(K)

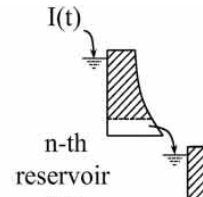

(K)

(a) Zoch and Clark single reservoir concept

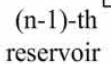

(K) (n-2)-th

(K)

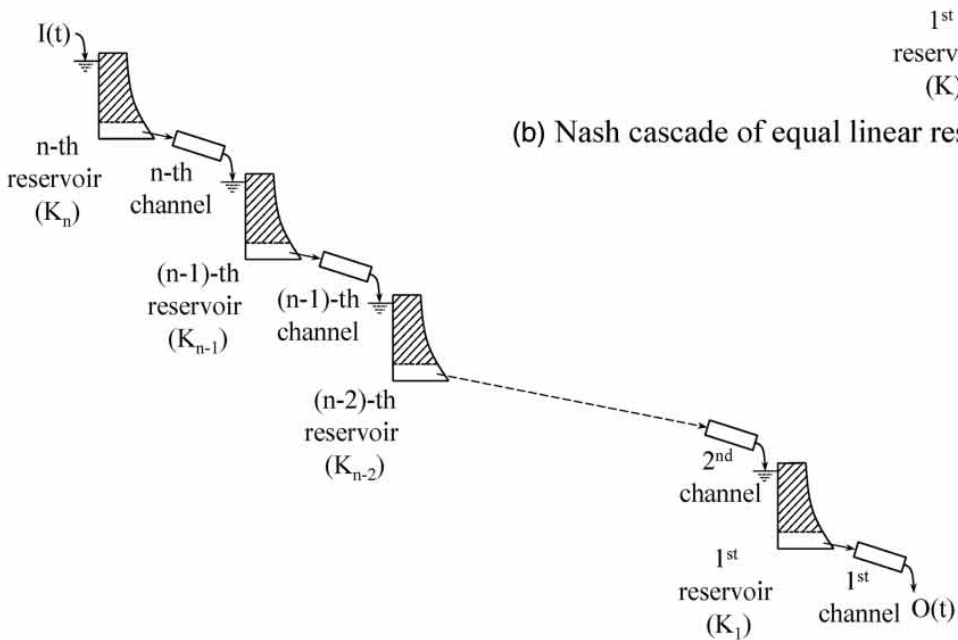

(c) Dooge cascade of reservoirs with channels for translation

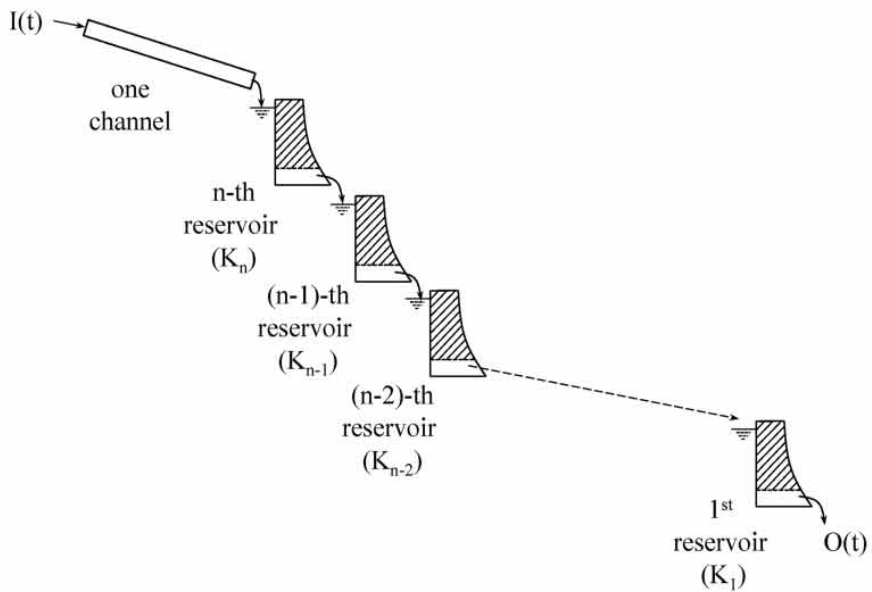

(d) Dooge simplified cascade with lumped channels positioned upstream of

Figure 2 | Conceptual watershed models of (a) Zoch/Clark, (b) Nash, (c) Dooge before lumping channels and (d) Dooge after lumping channels

The above review illustrates that historical development of the UH conceptual model has progressed from TA curves to linear channel systems, single reservoir to multiple reservoirs, equal to unequal storages, and simple to more complex formulations. Despite these improvements, some limitations remain. The isochronal, or TAC curve, method represents the physical process of watershed subareas contributing to the outlet hydrograph to some extent, but it 
does not consider flow attenuation, and the common practice of plotting isochrones equidistantly unrealistically suggests homogeneous flow transfer times throughout the watershed. In contrast with the TAC method, the UH method includes the attenuation, while this is the result of routing the flow through a system of reservoirs and channels rather than by representing the physical process of attenuation of flow. Dooge (1959) established a general theory of UH with channel-reservoir system but he did not provide an analytical solution for his original general equation of the UH, which he recognized would have involved impracticably complex and tedious calculation. Rather, Dooge (I959) simplified the problem by lumping the channels (Figure 2), and assuming that the order of the channel-reservoir system was immaterial and that the unrestricted reservoirs were all equal. In retrospect, Dooge's (I959) simplifying assumptions might seem unrealistic, but should be viewed in light of the limited understanding of watershed hydrology and relatively crude information technology available at that time. Another limitation is that, by adopting the assumption of uniformly distributed rainfall, the established $\mathrm{UH}$ methods are essentially constrained to relatively small watersheds $\left(<500 \mathrm{~km}^{2}\right.$ in area) where the distribution of rainfall can be regarded as homogeneous (Shaw 1994).

It is apparent from the literature that the theory of $\mathrm{UH}$ generated considerable research interest before the 1970s, but little progress has been made since. It is timely then to advance UH theory by overcoming the above mentioned limitations and simplifications, potentially allowing this approach to take advantage of modern technologies such as remote sensing, geographic information systems (GISs) and weather radar (Finsen et al. 2014; Kang \& Merwade 20I4; Wu et al. 20I5), improved understanding of catchment hydrology, and advancements in hydrological methods ( $\mathrm{Li}$ et al. 2008; Zhang et al. 2010).

The objective of this paper is to make a contribution to the development of UH theory by presenting a new physically distributed conceptualization of the linear reservoirchannel cascade that overcomes the limitations identified above. The new UH method proposed here includes a riverbed slope-based isochronal method that more realistically divides the watershed into runoff generation and transfer subareas. In each subarea, the runoff is attenuated by a reservoir and then translated downstream by channels. By considering both attenuation and translation processes, effective rainfall is progressively concentrated along the river so that the order of reservoirs and channels is of significance. The theoretical development of this new method, named general concentration curve (GCC), is outlined in the following section where it is also demonstrated that some well-known UH models are special cases of the GCC, differentiated only by their simplifying assumptions. Rainfall and runoff data from 18 historical storm events from Dagutai, Bailianhe and Kaifengyu watersheds in China are then used to demonstrate application of the GCC method and compare its performance with that of the Nash IUH.

\section{METHODOLOGY}

Derivation of the generalized concentration curve (GCC) method is presented here in four sections, with the first covering conceptual and theoretical development, the second describing the method for deriving the $S$ curve and UH of duration $\mathrm{T}$, the third showing a suggested method based on reach-averaged riverbed slope for determining the storage parameter, $K_{i}$, and translation time parameter, $\tau$, and the fourth briefly demonstrating the relationship between the new GCC method and existing concentration curves.

\section{Conceptual and theoretical development}

The transformation of effective rainfall to a runoff hydrograph is influenced by the processes of translation of flow by gravity without storage effects, and attenuation of flow due to resistance and storage effects. By conceptualizing a watershed simply as $n$ linearly arranged contributing subareas (Figure 1) and as a cascade of reservoirs separated by channels, the inflow to the $i$ th reservoir will be attenuated by the reservoir to produce an outflow that after translation through the channel will become the inflow to the $i-1$ reservoir, as well as the effective rainfall from the local subarea. Consecutive processing in this manner ultimately produces discharge at the outlet of the watershed (Figure 3). Only after the storage of $i$ reservoirs and the transposition of $i-1$ channels can the water from the $i$ th reservoir reach the outlet of the watershed. In this way, each subarea 


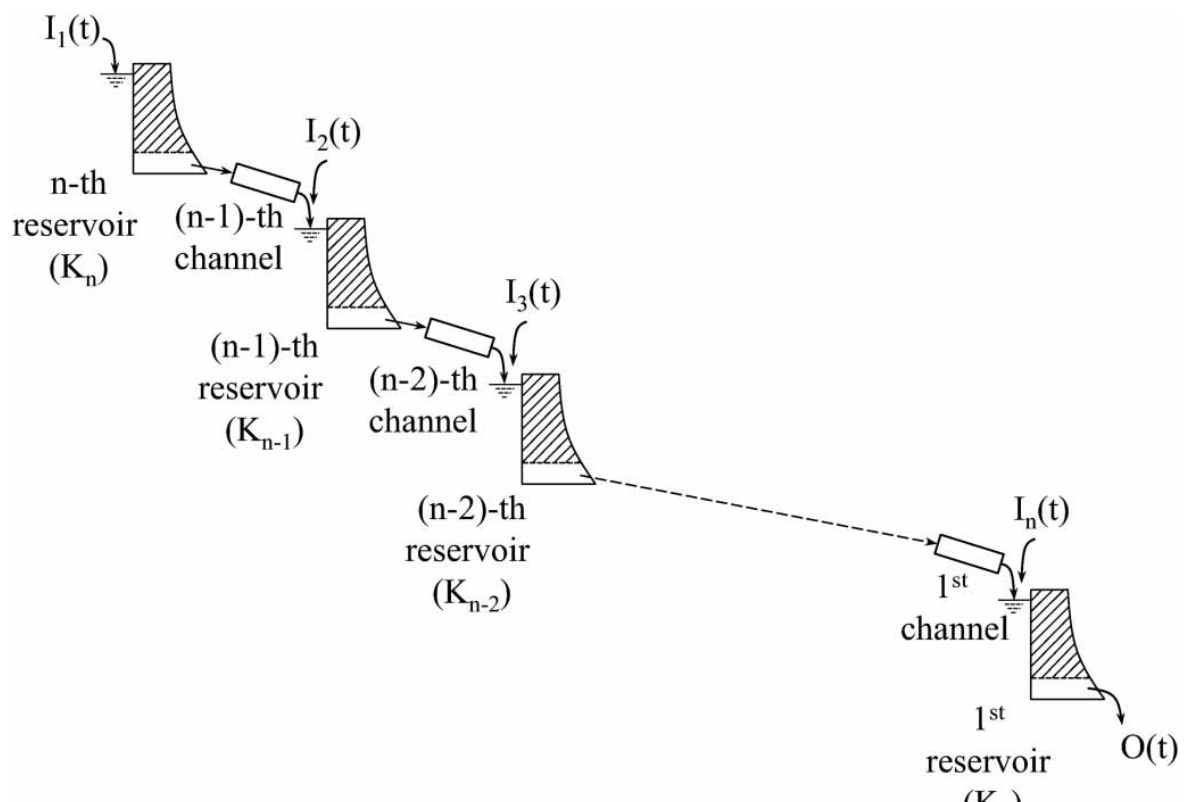

$\left(\mathrm{K}_{1}\right)$

Figure 3 | Conceptual concentration model comprising $n$ different linear reservoirs linked by $n-1$ linearly arranged channels.

contributes a UH at the outlet of the watershed. In a linear system, according to the superposition principle, the UH of the watershed is the linear combination of these individual UHs. This conceptualization of the watershed runoff system is similar to the initial cascade concept of Dooge (I959) (Figure 2), but we retained the channels between the reservoirs to explicitly consider the processes of flow translation and progressive concentration of rainfall excess down the river system. For the sake of completeness and clarity, the proposed method is derived below.

Suppose that each conceptual reservoir has a specific storage property $K_{i}$. We can establish the following equations in the $n=1$ subarea:

$I_{1}(t)-q_{1}(t)=\frac{d s_{1}(t)}{d t}$

$s_{1}(t)=K_{1} q_{1}(t)$

where $I_{1}(t)$ is the initial inflow to $n=1$ subarea, $q_{1}(t)$ is the corresponding initial outflow of $n=1$ subarea to the outlet of the whole watershed, and $s_{1}(t)$ is the corresponding initial water storage of $n=1$ subarea.
Differentiating on the variable $t$ for Equation (2) gives:

$\frac{d s_{1}(t)}{d t}=K_{1} \frac{d q_{1}(t)}{d t}$

Substituting Equation (3) into Equation (1) yields:

$q_{1}(t)=\frac{1}{K_{1} D+1} I_{1}(t)$

where $D$ is the differential operator $d / d t$. Similarly, during the initial period, for $n=2$ subarea the following equations apply:

$I_{2}(t)-q_{2}^{\prime}(t)=\frac{d s_{2}^{\prime}(t)}{d t}$

$s_{2}^{\prime}(t)=K_{2} q_{2}^{\prime}(t)$

Then, similar to Equation (4), substituting the differential of Equation (6) into Equation (5) gives:

$q_{2}^{\prime}(t)=\frac{1}{K_{2} D+1} I_{2}(t)$ 
where $q_{2}^{\prime}(t)$ is the initial outflow of $n=2$ subarea resulting from the corresponding initial inflow $\mathrm{I}_{2}(t)$ to $n=2$ subarea, $\mathrm{s}_{2}^{\prime}(t)$ is the reservoir storage of $n=2$ subarea generated by the initial inflow $\mathrm{I}_{2}(t)$ to $n=2$ subarea, and the meanings of other symbols are as previously defined.

The outflow of $n=2$ subarea will become the second time step inflow of $n=1$ subarea via translation through the linear channel over the time period of one $\tau$ to give:

$q_{2}^{\prime}(t-\tau)-q_{2}(t)=\frac{d s_{2}(t)}{d t}$

$s_{2}(t)=K_{1} q_{2}(t)$

where $\mathrm{q}_{2}(t)$ is the second time step outflow resulting from the corresponding second time step inflow $q_{2}^{\prime}(t-\tau)$ that occurred in $n=1$ subarea, $s_{2}(t)$ is the second time step reservoir storage in $n=1$ subarea generated by the inflow $q_{2}^{\prime}(t-\tau)$ from $n=2$ subarea, and the meanings of the other symbols are as previously defined.

Substituting Equation (7) into Equation (8) and integrating Equation (9) yields:

$q_{2}(t)=\frac{1}{\left(K_{1} D+1\right)\left(K_{2} D+1\right)} I_{2}(t-\tau)$

Similarly, for the $i$ th subarea,

$q_{i}(t)=\frac{1}{\left(K_{1} D+1\right)\left(K_{2} D+1\right) \cdots\left(K_{i} D+1\right)} I_{i}[t-(i-1) \tau]$

Suppose that the initial values of $q_{i}(t)$ and its derivatives of different orders are all equal to 0 , i.e. $q(0)=$ $q^{\prime}(0)=q^{\prime \prime}(0)=\cdots=q^{n-1}(0)=0$, then according to the differential principle of Laplace transform, Equation (11) can be changed to:

$$
\begin{aligned}
L\left[q_{i}(t)\right]= & \frac{1}{\left(K_{1} p+1\right)\left(K_{2} p+1\right) \cdots\left(K_{i} p+1\right)} L\left[I_{i}(t-(i\right. \\
& -1) \tau)]
\end{aligned}
$$

where $L[\ldots]$ denotes the Laplace transform and $p$ is the Laplace variable, often called the complex frequency, and the meanings of the other symbols area are as previously defined.
According to the time delay property of the Laplace transform:

$L\left[I_{i}(t-(i-1) \tau)\right]=e^{-(i-1) \tau p} L\left[I_{i}(t)\right]$

Substituting Equation (13) into Equation (12) yields

$L\left[q_{i}(t)\right]=\frac{1}{\left(K_{1} p+1\right)\left(K_{2} p+1\right) \cdots\left(K_{i} p+1\right)} e^{-(i-1) \tau p} L\left[I_{i}(t)\right]$

Suppose that the inflow is an instantaneous pulse, i.e. $I_{i}(t)=\delta(t)$, according to impulse response principles, the outflow will be the IUH $u(t)$. Therefore, Equation (14) can be rewritten as:

$$
\begin{aligned}
L\left[u_{i}(t)\right] & =\frac{1}{\left(K_{1} p+1\right)\left(K_{2} p+1\right) \cdots\left(K_{i} p+1\right)} e^{-(i-1) \tau p} L[\delta(t)] \\
& =\frac{1}{\left(K_{1} p+1\right)\left(K_{2} p+1\right) \cdots\left(K_{i} p+1\right)} e^{-(i-1) \tau p}
\end{aligned}
$$

The inverse Laplace transform yields:

$u_{i}(t)=\sum_{j=1}^{i} \frac{K_{j}^{i-2} e^{-\frac{t-(i-1) \tau}{K_{j}}}}{\prod_{\substack{m=1 \\ m \neq j}}^{i}\left(K_{j}-K_{m}\right)}$

The storage parameter $K_{i}$ is also called the time lag of water storage of each reservoir. Equation (16) differs from the general equation in the 'Combinations of Channels and Reservoirs' configuration of Dooge (1959) in the power of the exponent. The translation time illustrated in the power of the proposed GCC exponential decay curve varies with the order of reservoirs and channels. This is because the effective rainfall is progressively routed along the river in the GCC method. The water near the watershed outlet is translated with a shorter distance than that far away from the outlet. In this case, the order of reservoirs and channels is important.

The superposition principle applies to a linear system, so the UH of the watershed is the summation of the product of each subarea's UH to the watershed outlet and its corresponding weight:

$u(t)=\omega_{1} u_{1}(t)+\omega_{2} u_{2}(t)+\omega_{3} u_{3}(t)+\cdots+\omega_{n} u_{n}(t)$ 
Finally,

$u(t)=\sum_{i=1}^{n} \omega_{i} \sum_{j=1}^{i} \frac{K_{j}^{i-2} e^{-\frac{t-(i-1) \tau}{K_{j}}}}{\prod_{\substack{m=1 \\ m \neq j}}^{i}\left(K_{j}-K_{m}\right)}$

where $\omega_{\mathrm{i}}$ is the area weight of isochrones.

Equation (18) is the final integrated form of the new IUH that we named the GCC for predicting storm flow. Given the separation of the UH description as a sum of the contributions of the different subareas, each term of the UH can be convoluted separately using corresponding effective rainfall $I_{i}$ estimated in each subarea of the watershed. The spatial variability of rainfall of the whole watershed can be considered in this manner. The corresponding equation can be expressed as:

$$
\begin{aligned}
Q(k) & =\sum_{i=1}^{n} Q_{i}(k) \\
& =\sum_{i=1}^{n} \sum_{t=1}^{t u_{i}}\left[I_{i}(k-t+1) \omega_{i} \sum_{j=1}^{i} \frac{K_{j}^{i-2} e^{-\frac{t-(i-1) \tau}{K_{j}}}}{\prod_{\substack{m=1 \\
m \neq j}}^{i}\left(K_{j}-K_{m}\right)}\right]
\end{aligned}
$$

where $Q(k)$ is the outflow of the entire watershed, $Q_{i}(k)$ is the outflow contributed to the watershed outlet from the $i$ th subarea, $I_{i}(k)$ is the effective rainfall in the $i$ th subarea, $t u_{i}$ is the length of $\mathrm{UH}$ in the $i$ th subarea, and the meanings of the other symbols are as previously defined.

\section{Derivation of $S$ curve and UH of duration $T$ (TUH)}

The IUH is derived under the assumption that the input is one instantaneous pulse, which is unrealistic, so the UH of duration $T$ (TUH) must be transferred in order to convert an effective rainfall into surface flow (Chow et al. I988; Li et al. 2008). Fortunately, the $S$ curve can be applied to obtain the TUH from the IUH. The $S$ curve, or $S$ hydrograph, is defined as the runoff response to unit intensity of effective rainfall from the beginning to time $t$ and continues indefinitely, close to unity. The $S$ curve and TUH are derived below.

The $S$ curve can be derived from the definition:

$$
\begin{aligned}
S(t) & =\int_{0}^{t} u(t) d t \\
& =\int_{0}^{t}\left[\sum_{i=1}^{n} \omega_{i} \sum_{j=1}^{i} \frac{K_{j}^{i-2} e^{-\frac{t-(i-1) \tau}{K_{j}}}}{\prod_{\substack{m=1 \\
m \neq j}}^{i}\left(K_{j}-K_{m}\right)}\right] d t \\
& =\sum_{i=1}^{n} \omega_{i} \sum_{j=1}^{i}\left[\frac{K_{j}^{i-2}}{\prod_{\substack{i \\
m=1 \\
m \neq j}}^{t}\left(K_{j}-K_{m}\right)} \int_{0}^{-\frac{t-(i-1) \tau}{K_{j}}} d t\right] \\
& =\sum_{i=1}^{n} \omega_{i} \sum_{j=1}^{i}\left\{\frac{K_{j}^{i-1}}{\prod_{\substack{i \\
m=1 \\
m \neq j}}\left(K_{j}-K_{m}\right)}\left[1-e^{-\frac{t-(i-1) \tau}{K_{j}}}\right]\right.
\end{aligned}
$$

$$
\begin{aligned}
& u(T, t)=\frac{S(t)-S(t-T)}{T} A \\
& \left.=\frac{A}{T}\left\{\sum_{i=1}^{n} \omega_{i} \sum_{j=1}^{i}\left[\frac{K_{j}^{i-1}}{\prod_{\substack{m=1 \\
m \neq j}}^{i}\left(K_{j}-K_{m}\right)}\left(1-e^{\left.-\frac{t-(i-1) \tau}{K_{j}}\right)}\right]-\sum_{i=1}^{n} \omega_{i} \sum_{j=1}^{i}\left[\frac{K_{j}^{i-1}}{\prod_{\substack{m=1 \\
m \neq j}}^{i}\left(K_{j}-K_{m}\right)}\right]-\frac{t-T-(i-1) \tau}{K_{j}}\right)\right]\right\} \\
& =\frac{A}{T} \sum_{i=1}^{n} \omega_{i} \sum_{j=1}^{i}\left[\frac{K_{j}^{i-1}}{\prod_{\substack{m=1 \\
m \neq j}}^{i}\left(K_{j}-K_{m}\right)} e^{-\frac{t-(i-1) \tau}{K_{j}}}\left(e^{\frac{T}{K_{j}}}-1\right)\right]
\end{aligned}
$$


where for each subarea, when $\mathrm{t}<(\mathrm{i}-1) \tau, u(t)=0$ and $\mathrm{S}(t)=0$, so $t$ must be larger than or equal to $(\mathrm{i}-1) \tau$.

Then the TUH, $\mathrm{u}(T, t)$, can be derived as follows: where $T$ is the time step of $\mathrm{UH}$, often determined by the time step of effective rainfall series, and $A$ is the watershed area.

\section{Determination of the parameters in each subarea}

It is plausible that there are numerous parameters in the GCC method, such as area weights $\omega_{i}$ and storage coefficient $K_{i}$ for each subarea, and translation time $\tau$ for the channels. In reality, the area weights are predefined by the isochronal lines (Zhang et al. 20I0), details of which can be obtained from the Appendix to this paper. The isochronal lines are plotted according to the riverbed slope rather than as equidistant lines, which makes the isochronal lines more physically-based. The riverbed slope is utilized not only in determination of isochronal lines, but also in deriving storage coefficient $K_{i}$ for each subarea from the watershed average storage coefficient $K$, as suggested by Li et al. (2008). The number of reservoirs, or the number of isochronal lines, is assured to be an integer by adding 1 to the integer part of the determined Nash IUH $n$. Once the watershed averaged storage coefficient $K$ is determined, either by the moment method (Nash I957) or calibration algorithms, each storage coefficient, $K_{i}$, for an unequal-reservoir cascade IUH model can be calculated by (Li et al. 2008):

$K_{i}=\frac{n \times K}{\sqrt{i_{j}} \times \sum_{l=1}^{n} \frac{1}{\sqrt{i_{l}}}} \quad j=1,2, \cdots, n$

where $i_{j}$ is slope of $j$ th subarea of the watershed, and the meanings of the other symbols are as previously defined.

Therefore, there are only three parameters in the GCC method, i.e. the number of reservoirs $n$, watershed average storage coefficient $K$ and channel translation time $\tau$.

\section{Relationships between the new GCC and existing concentration curves}

The GCC is 'generalized' in the sense that some common UHs can be shown to be special cases of this new formulation, but with specific parameters $n, K$ and $\tau$. Five examples are illustrated below:

1. When $n=1, \quad K_{1}=\mathrm{K}$, and $K_{2}=K_{3}=\cdots=K_{n}=0$, Equation (18) becomes:

$$
u(t)=\frac{1}{K} e^{-\frac{t}{K}}
$$

which is the Clark concentration curve (Clark 1945).

2. When $\tau=0$ and $K_{1}=K_{2}=K_{3}=\cdots=K_{n}=K$, Equation (18) becomes:

$$
\begin{aligned}
& u(t)=\frac{1}{K} e^{-\frac{t}{K}}\left[\omega_{1}+\omega_{2}\left(\frac{t}{K}\right)+\frac{\omega_{3}}{2 !}\left(\frac{t}{K}\right)^{2}+\frac{\omega_{4}}{3 !}\left(\frac{t}{K}\right)^{3}+\cdots+\right. \\
& \left.\frac{\omega_{n}}{(n-1 !}\left(\frac{t}{K}\right)^{n-1}\right]=\frac{1}{K} P_{m}
\end{aligned}
$$

which is the Kalinin-Milyukov concentration curve (Kalinin \& Milyukov 1957). The Kalinin-Milyukov method does not explicitly consider the influence of water translation, so its translation time, $\tau$, is actually the time lag of water storage, $K$.

3. When $\tau=0, K_{1}=K_{2}=K_{3}=\cdots=K_{n}=K$, and if all effective rainfall begins in the $n$th subarea, Equation (18) can be written as:

$$
u(t)=\frac{1}{K \Gamma(n)}\left(\frac{t}{K}\right)^{n-1} e^{-\frac{t}{K}}
$$

which is the Nash concentration curve, otherwise known as the Nash IUH or gamma function (Nash I957, I960).

4. When $\tau>0, K_{1}=K_{2}=K_{3}=\cdots=K_{n}=K$, and if all effective rainfall begins in $n$th subarea and taking the channel translation effort into consideration, Equation (18) can be written as:

$$
u(t)=\frac{1}{K \Gamma(n)}\left[\frac{t-(n-1) \tau}{K}\right]^{n-1} e^{-\frac{t-(n-1) \tau}{K}}
$$

which is the Wang concentration curve (Wang 1982), the cascade system of which was composed of $n$ equal reservoirs and $n-1$ channels. 
5. When $\tau>0$ and all effective rainfall is routed from the river headwater, Equation (18) can be written as:

$$
u(t)=\int_{0}^{t} \frac{\delta(t-\tau)}{\prod\left(1+K_{i} D\right)} \omega\left(\tau^{\prime}\right) d \tau
$$

where $\omega\left(\tau^{\prime}\right)$ is the subarea weight. This is the general equation of Dooge (I959). While Dooge (I959) did not give the analytical solution to Equation (27), he assumed that all the linear reservoirs were identical to derive the analytical solution in the form of a Poisson probability function.

\section{Metrics for method evaluation}

The performance of the GCC method was compared with that of the Nash IUH method. Three goodness-of-fit metrics were used to evaluate performance of the models in simulating the observed hydrographs: the Nash-Sutcliffe coefficient (Nash \& Sutcliffe 1970)] ( $\left.E_{\mathrm{NS}}\right)$, the water balance efficiency $\left(E_{\mathrm{WB}}\right)$, and the peak discharge error (PDE), calculated as:

$E_{\mathrm{NS}}=1-\frac{\sum_{t=1}^{n}(Q(t)-\hat{Q}(t))^{2}}{\sum_{t=1}^{n}(Q(t)-\bar{Q})^{2}}$

$E_{\mathrm{WB}}=\frac{\sum_{t=1}^{n} \hat{Q}(t)-\sum_{t=1}^{n} Q(t)}{\sum_{t=1}^{n} Q(t)} \times 100 \%$

$\mathrm{PDE}=\left|\frac{\hat{Q}_{\text {peak }}-Q_{\text {peak }}}{Q_{\text {peak }}}\right| \times 100 \%$

where $t$ is the time index, $Q(t)$ is observed flow, $\hat{Q}(t)$ is simulated flow, $\bar{Q}$ is the mean of observed flow, $Q_{\text {peak }}$ is the peak flow for observed data, and $\hat{Q}_{\text {peak }}$ is the corresponding simulated peak value. Good model performance was judged by achievement of values of $E_{\mathrm{NS}}$ close to unity and values of $E_{\mathrm{WB}}$ and PDE close to zero.

\section{STUDY AREA AND DATA}

The GCC method was verified using data from the Dagutai, Bailianhe and Kaifengyu watersheds, located in the middle reaches of the Han River, the largest tributary of the Yangtze River, China (Figure 4). All watersheds are within the subtropical monsoon climate zone. A digital elevation model (DEM) of each watershed was derived from shuttle radar topographic mission data, obtained from consortium for spatial information (http://srtm.csi.cgiar.org/) at a $90 \mathrm{~m}$ grid resolution. The Yangtze River Commission of the Ministry of Water Resources, P.R. China provided 6-hourly rainfall and instantaneous runoff data measured every 6 hours from each watershed. From these data a total of 18 representative storm events were selected for analysis (Table 1), with six events from the Dagutai watershed with four rain gauges, seven events from the Bailianhe watershed with 14 rain gauges and five events from the Kaifengyu watershed with 29 rain gauges

The Dagutai watershed covers an area of $727 \mathrm{~km}^{2}$ located between longitude $111^{\circ} 25^{\prime} \mathrm{E}$ and $111^{\circ} 48^{\prime} \mathrm{E}$ and latitude $31^{\circ} 21^{\prime} \mathrm{N}$ and $31^{\circ} 42^{\prime} \mathrm{N}$. The Dagutai River is $65.6 \mathrm{~km}$ long, with the elevation ranging from $1,158 \mathrm{~m}$ above mean sea level (a.m.s.l.) in the headwaters to $268 \mathrm{~m}$ a.m.s.l. at the outlet. Average annual precipitation is $1,003.6 \mathrm{~mm}$, of which 85\% occurs from April to October.

The Bailianhe watershed covers an area of $1,800 \mathrm{~km}^{2}$ located between longitude $115^{\circ} 31^{\prime} \mathrm{E}$ and $116^{\circ} 4^{\prime} \mathrm{E}$ and latitude $30^{\circ} 39^{\prime} \mathrm{N}$ and $31^{\circ} 9^{\prime} \mathrm{N}$. The river originates in the Dabie Mountain and has two main branches with lengths of $72 \mathrm{~km}$ and $63 \mathrm{~km}$, respectively. The elevation varies from $464 \mathrm{~m}$ a.m.s.l. in the headwaters to $96 \mathrm{~m}$ a.m.s.l. at the outlet, which also corresponds with the inlet to Bailianhe Reservoir. Average annual precipitation is $1,366 \mathrm{~mm}$, of which $85 \%$ occurs from June to August. The Bailianhe watershed is prone to flood hazard, and accurate flood forecasting is important for management of the Bailianhe Reservoir.

The Kaifengyu watershed covers an area of $5,253 \mathrm{~km}^{2}$ located between longitude $110^{\circ} 16^{\prime} \mathrm{E}$ and $111^{\circ} 25^{\prime} \mathrm{E}$ and latitude $31^{\circ} 26^{\prime} \mathrm{N}$ and $32^{\circ} 24^{\prime} \mathrm{N}$. The Kaifengyu River rises on the southern side of Shennongjia Mountain and falls $470 \mathrm{~m}$ over its $140 \mathrm{~km}$ long course. Average annual precipitation ranges from $855 \mathrm{~mm}$ in the north to $1,140 \mathrm{~mm}$ in the 


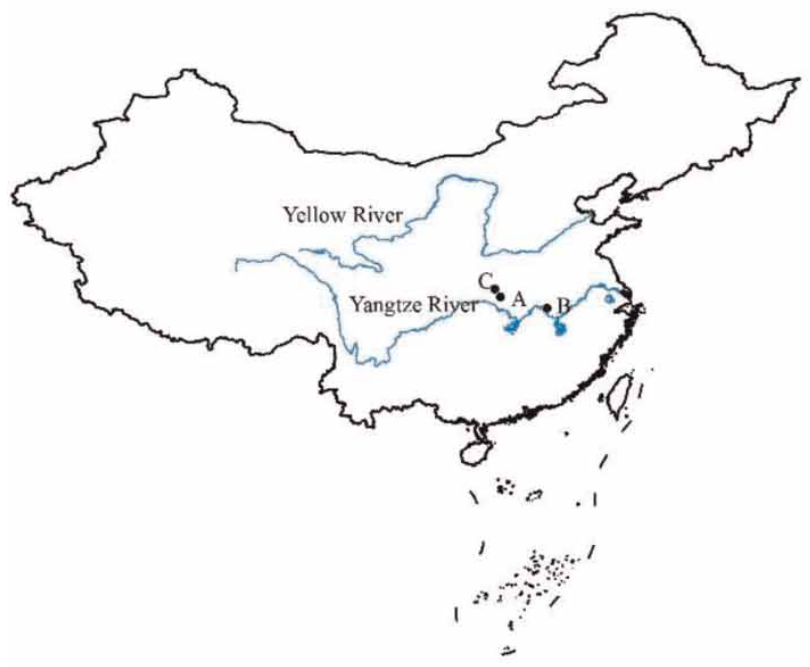

(1) Locations in China

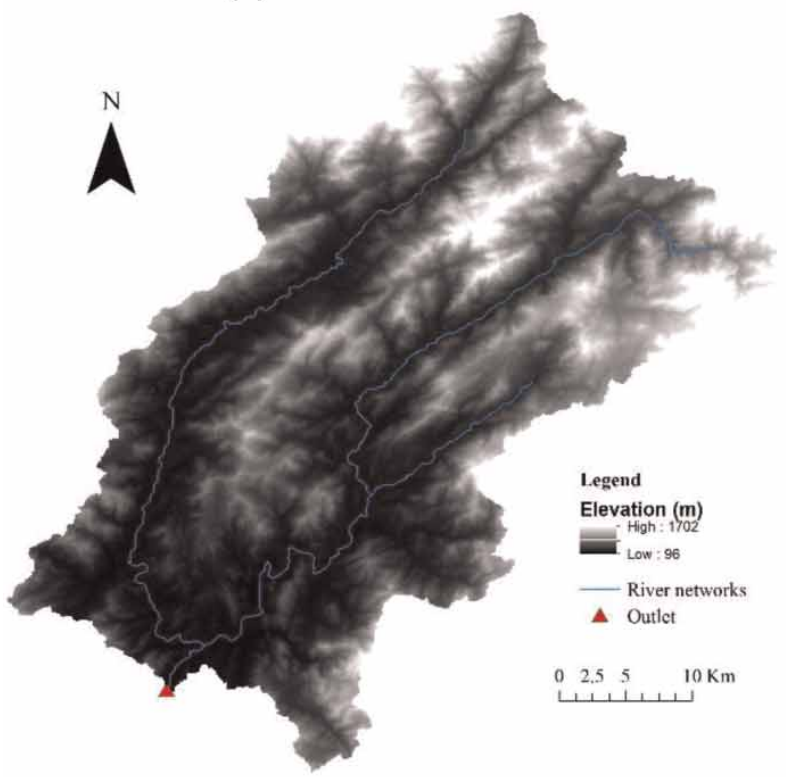

(b) The Bailianhe watershed

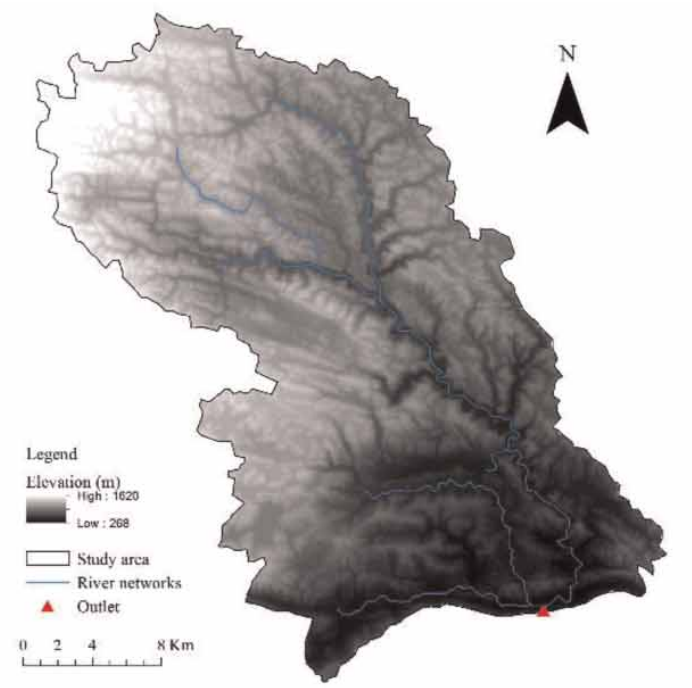

(a): The Dagutai watershed

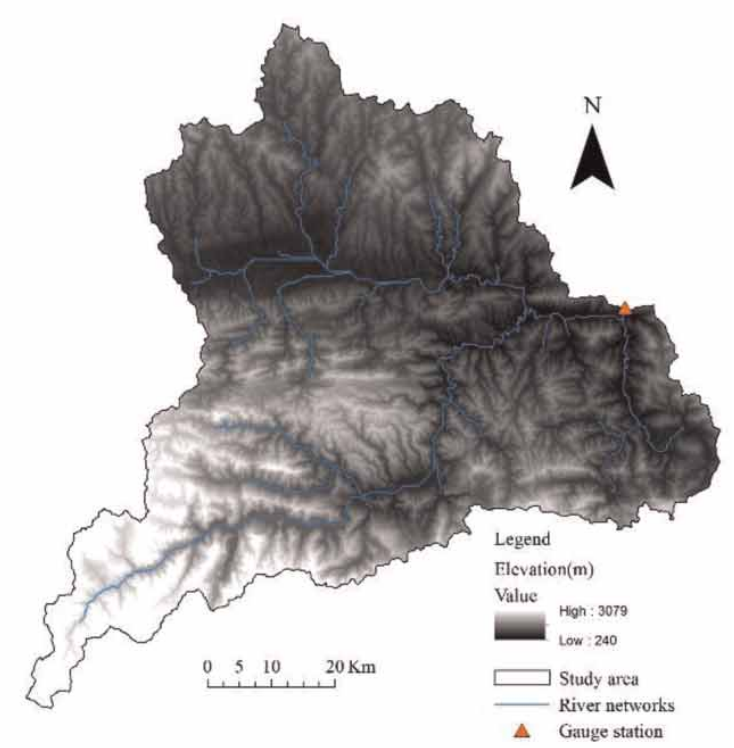

(c) The Kaifengyu watershed

Figure 4 | Location, elevation and river networks in the Dagutai, Bailianhe and Kaifengyu watersheds.

south of the watershed, with most rain falling from June to September.

\section{RESULTS AND DISCUSSIONS}

The main purpose of this paper was the introduction and verification of the GCC method. Investigation of the runoff generation process was not our focus, so a traditional and reliable runoff generation method was sufficient for our purpose. The direct runoff hydrograph (DRH) was separated from base flow using the objective and repeatable digital filter method (Chapman 1999). The effective rainfall hyetograph (ERH) was derived according to the traditional precipitation-runoff correlation diagram derived from the API Model (Sittner et al. I969), which has previously been 
Table 1 | Characteristics of the storm events from the study areas selected for analysis

\begin{tabular}{|c|c|c|c|c|c|c|c|c|c|c|}
\hline Watershed & $\begin{array}{l}\text { Area } \\
\left(\mathbf{k m}^{2}\right)\end{array}$ & $\begin{array}{l}\text { Number of } \\
\text { rain gauge } \\
\text { stations }\end{array}$ & $\begin{array}{l}\text { Storm } \\
\text { ID }\end{array}$ & Date & $\begin{array}{l}\text { Average total rainfall } \\
\text { volume from rain } \\
\text { gauges }(\mathrm{mm})\end{array}$ & $\begin{array}{l}\text { Maximum total } \\
\text { rainfall volume from } \\
\text { rain gauges }(\mathrm{mm})\end{array}$ & $\begin{array}{l}\text { Minimum total } \\
\text { rainfall volume from } \\
\text { rain gauges }(\mathrm{mm})\end{array}$ & $\begin{array}{l}\text { Max/ } \\
\text { Min }\end{array}$ & $\begin{array}{l}\text { Coefficient } \\
\text { of spatial } \\
\text { variation }^{\mathrm{a}}\end{array}$ & $\begin{array}{l}\text { Peak } \\
\text { discharge } \\
\left(\mathrm{m}^{3} / \mathrm{s}\right)\end{array}$ \\
\hline \multirow[t]{6}{*}{ Dagutai } & \multirow[t]{6}{*}{727} & \multirow[t]{6}{*}{4} & 1 & 19740809 & 36.6 & 55.7 & 19.7 & 2.83 & 1.06 & 141 \\
\hline & & & 2 & 19780529 & 28.4 & 31.2 & 27.6 & 1.13 & 0.14 & 58 \\
\hline & & & 3 & 19780624 & 96.1 & 126.2 & 74.7 & 1.69 & 0.61 & 93 \\
\hline & & & 4 & 19800820 & 41.0 & 43.6 & 36.7 & 1.19 & 0.15 & 84 \\
\hline & & & 5 & 19820809 & 71.3 & 181 & 25.0 & 7.24 & 2.32 & 265.6 \\
\hline & & & 6 & 19830811 & 32.0 & 62.7 & 23.9 & 2.62 & 1.37 & 155 \\
\hline \multirow[t]{7}{*}{ Bailianhe } & \multirow[t]{7}{*}{1800} & \multirow[t]{7}{*}{19} & 7 & 19790626 & 213.4 & 286 & 145.0 & 1.97 & 0.73 & 2774 \\
\hline & & & 8 & 19790629 & 100.8 & 125 & 28.0 & 4.46 & 1.01 & 857 \\
\hline & & & 9 & 19810627 & 127.8 & 249.1 & 58.4 & 4.26 & 1.13 & 1936 \\
\hline & & & 10 & 19820614 & 121.2 & 198.3 & 55.1 & 3.60 & 1.22 & 1597 \\
\hline & & & 11 & 19850620 & 69.9 & 76.8 & 60.8 & 1.26 & 0.22 & 1027 \\
\hline & & & 12 & 19860706 & 74.4 & 142.9 & 85.2 & 1.68 & 0.80 & 1542 \\
\hline & & & 13 & 19870820 & 160.0 & 256.9 & 107.3 & 2.39 & 0.91 & 3336 \\
\hline \multirow[t]{5}{*}{ Kaifengyu } & \multirow[t]{5}{*}{5253} & \multirow[t]{5}{*}{24} & 14 & 19760531 & 43.8 & 90.9 & 15.8 & 5.75 & 1.76 & 1173 \\
\hline & & & 15 & 19800623 & 97.8 & 142.2 & 67.7 & 2.10 & 0.78 & 2300 \\
\hline & & & 16 & 19800824 & 47.4 & 90.1 & 38.2 & 2.36 & 0.67 & 1117 \\
\hline & & & 17 & 19800827 & 55.7 & 186 & 28.0 & 6.64 & 3.58 & 976 \\
\hline & & & 18 & 19800907 & 51.4 & 71.1 & 45.3 & 1.57 & 0.33 & 1,173 \\
\hline
\end{tabular}

${ }^{a}$ Coefficient of spatial variation was calculated by (max-min)/average. A uniform distributed rainfall was evaluated by the values of coefficient of spatial variation close to zero and values of $\mathrm{max} / \mathrm{min}$ close to one.

successfully applied in humid and semi-humid regions of China (Zhang 2010). Appropriate values were assigned for the model parameters, including maximum areal mean tension water storage $W_{m}(\mathrm{~mm})$ for each watershed, and initial soil moisture $W_{O}(\mathrm{~mm})$ for each storm (Table 2). The

Table 2 | Parameters for derivation of the ERH

\begin{tabular}{lllll} 
Watershed & Storm ID & Period & $\mathbf{W}_{\mathbf{0}}(\mathbf{m m})$ & $\mathbf{W}_{\mathbf{m}} \mathbf{( \mathbf { m m } )}$ \\
\hline Dagutai & 1 & Calibration & 92 & 110 \\
& 2 & Calibration & 20 & 110 \\
& 3 & Calibration & 42 & 110 \\
& 4 & Calibration & 50 & 110 \\
Bailianhe & 5 & Verification & 87 & 110 \\
& 6 & Verification & 107 & 110 \\
& 8 & Calibration & 72 & 135 \\
& 9 & Calibration & 93 & 135 \\
& 10 & Calibration & 45 & 135 \\
& 11 & Calibration & 15 & 135 \\
& 12 & Verification & 72 & 135 \\
& 13 & Verification & 114 & 135 \\
& 14 & Verification & 53 & 135 \\
& 14 & Calibration & 43 & 100 \\
& 15 & Calibration & 86 & 100 \\
& 16 & Calibration & 32 & 100 \\
& 17 & Verification & 40 & 100 \\
& 18 & Verification & 33 & 100 \\
& & & &
\end{tabular}

isochrones of the watershed were determined from the DEM by the method of Zhang et al. (2010) using GIS software. GIS was also used to measure the reach-average riverbed slopes for each subarea from the DEM (Table 3).

The 18 storms from the three watersheds were divided into two groups: one for calibration and the other for verification (Table 2). The parameters of the Nash and GCC IUH were derived from the minimum sum of squares achieved by the SCE-UA algorithm (Duan et al. 1993) with the calibration storms. The different storage coefficient parameters $K_{j}$ for the unequal reservoirs were derived according to Equation (22) (Table 3). The area weight of each subarea and parameters of the Nash and GCC methods were derived using the described procedures (Table 3). These estimated parameters were used in the models to derive 6-hourly UHs. The UHs were convoluted with the ERHs to derive the DRHs (Figure 5). For the remaining verification storms, the DRHs were derived directly using the calibrated parameters as a test of their validity.

\section{Comparison with Nash IUH}

The isochrones drawn by the method of Zhang et al. (2010) were completely different from equidistant lines. For 
example, Dagutai watershed was divided according to the method of Zhang et al. (2010) into an upper subarea of $29 \mathrm{~km}$ length and a lower subarea of $16 \mathrm{~km}$ length, with corresponding subarea weights of 0.69 and 0.31 , respectively (Table 3). Had the isochrones been drawn from equidistant lines, the watershed would have been divided into equal upper and lower lengths with corresponding subarea weights of about 0.54 and 0.46 , respectively. The method of Zhang et al. (2010) produced upper stream subareas much larger than the lower subareas, while the equidistant lines method results in relatively small differences in area. The reason for this is that the method of Zhang et al. (2010) plots isochronal lines based on riverbed slope, rather than distance from the outlet (Appendix). The upper headwater area of Dagutai watershed is mountainous with steep slopes (mean 0.025) while the downstream area is plain with low slopes (mean 0.006) (Table 3), implying higher flow velocities in the upper stream than in the lower stream. Therefore, for the same translation time, the upper stream translation distance was longer than that of the lower one. For the three watersheds investigated, the larger watershed area was associated with a greater number of subareas, which reflects the greater heterogeneity of larger watersheds.

The calculated reservoir storage coefficient $(K)$ of GCC was of the same magnitude as that of Nash, which indicated that the SCE-UA algorithm was appropriate for derivation of $K$ and translation time $(\tau)$ with a pre-determined number of reservoirs $(n)$. Due to a slightly larger value of $n$, most calculated $K$ values of GCC were a little smaller than those of Nash, while the time required for water to move from the river headwaters to its outlet which is often presented by NK (Singh 1990), was almost the same between the two methods. Therefore, the derived GCC UHs compared reasonably with the Nash IUHs.

After applying the derived UHs to hydrograph prediction, visual comparison of the observed and predicted hydrographs of GCC and Nash method (Figure 5) suggested that the GCC method generally provided better predictions than the Nash method with respect to the magnitude of the peak, and the timing of the rise, peak and recession. This was supported by the goodness-of-fit statistics (Table 4). In the calibration period, the average values of $E_{\mathrm{NS}}, E_{\mathrm{WB}}$, and PDE of the three watersheds were $87.90 \%$, 


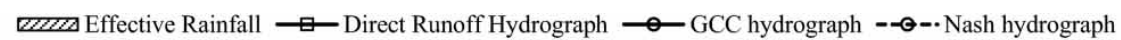
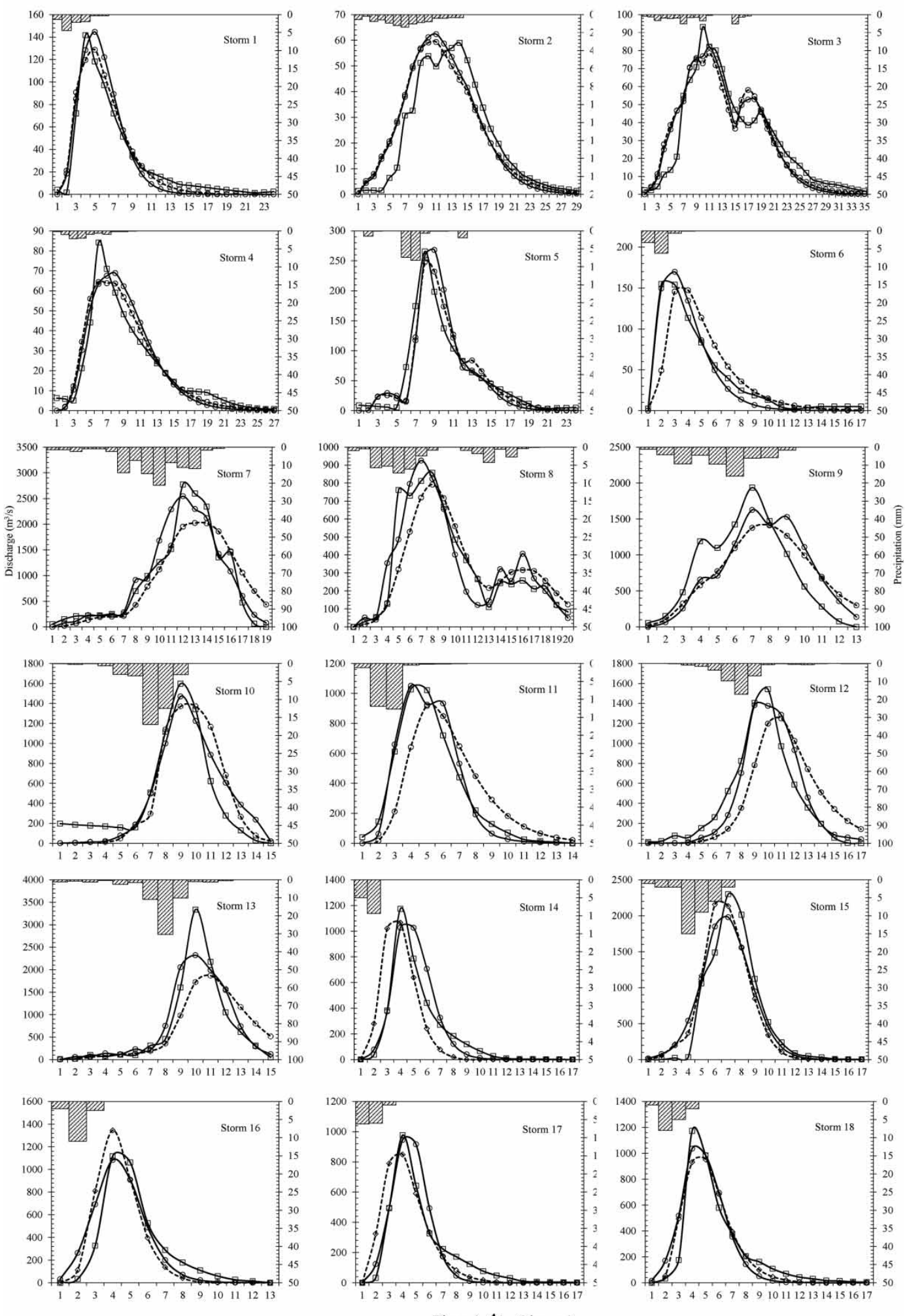

Time ( $\Delta t=6$ hours)

Figure 5 | Comparison of observed and calculated DRHs for 18 storms. 
Table 4 Goodness of fit statistics between predicted and observed DRHs in three study areas for GCC and Nash hydrograph

\begin{tabular}{|c|c|c|c|c|c|c|c|}
\hline \multirow[b]{2}{*}{ Catchment } & \multirow[b]{2}{*}{ Storm ID } & \multicolumn{3}{|c|}{ GCC hydrograph } & \multicolumn{3}{|c|}{ Nash hydrograph } \\
\hline & & $E_{\mathrm{NS}}(\%)$ & $E_{\mathrm{WB}}$ & PDE (\%) & $E_{\mathrm{NS}}(\%)$ & $E_{\mathrm{WB}}$ & PDE (\%) \\
\hline \multirow[t]{6}{*}{ Dagutai } & 1 & 95.30 & 1.00 & 1.99 & 92.39 & 1.00 & -9.21 \\
\hline & 2 & 86.28 & 1.04 & 5.75 & 85.20 & 1.03 & 0.58 \\
\hline & 3 & 89.41 & 1.00 & 11.90 & 86.20 & 1.00 & 15.66 \\
\hline & 4 & 91.80 & 1.00 & 18.12 & 89.90 & 1.00 & 23.43 \\
\hline & 5 & 90.79 & 1.00 & 0.97 & 84.67 & 0.99 & 6.75 \\
\hline & 6 & 86.87 & 0.95 & 9.61 & 68.35 & 0.93 & 4.88 \\
\hline \multirow[t]{7}{*}{ Bailianhe } & 7 & 91.66 & 1.02 & 8.34 & 83.14 & 0.96 & 27.09 \\
\hline & 8 & 84.19 & 0.99 & 8.00 & 80.68 & 0.97 & 7.60 \\
\hline & 9 & 70.10 & 1.00 & 3.17 & 68.00 & 0.96 & 5.39 \\
\hline & 10 & 87.12 & 0.99 & 7.99 & 79.90 & 1.00 & 14.17 \\
\hline & 11 & 95.59 & 1.00 & 2.29 & 73.04 & 0.99 & 10.46 \\
\hline & 12 & 84.55 & 0.99 & 10.36 & 75.32 & 0.97 & 18.99 \\
\hline & 13 & 87.47 & 1.03 & 30.46 & 68.65 & 0.93 & 44.08 \\
\hline \multirow[t]{5}{*}{ Kaifengyu } & 14 & 90.30 & 1.06 & 12.55 & 74.27 & 0.95 & 9.19 \\
\hline & 15 & 92.36 & 1.00 & 13.95 & 90.51 & 1.00 & 6.31 \\
\hline & 16 & 86.58 & 1.01 & 3.02 & 78.60 & 1.00 & 20.39 \\
\hline & 17 & 88.00 & 1.01 & 3.07 & 82.95 & 1.01 & 13.03 \\
\hline & 18 & 90.25 & 1.00 & 11.67 & 89.00 & 0.98 & 18.87 \\
\hline
\end{tabular}

1.01 and $8.71 \%$, respectively, for the GCC method and $82.49 \%, 0.99$ and $12.58 \%$, respectively, for the Nash method. The best values of $E_{\mathrm{NS}}, E_{\mathrm{WB}}$, and PDE were $95.30 \%, 1.00$ and 1.99\%, respectively, for the GCC method and $92.39 \%, 1.00$ and $0.58 \%$, respectively, for the Nash method. The worst values of $E_{\mathrm{NS}}, E_{\mathrm{WB}}$, PDE were $70.10 \%$, 1.06 and $18.12 \%$, respectively, for the GCC method and $68.00 \%, 0.95$ and $27.09 \%$, respectively, for the Nash method. Similar results were obtained in the verification period.

In the verification period, the average values of $E_{\mathrm{NS}}$, $E_{\mathrm{WB}}$, and PDE of the three watersheds were $89.06 \%, 1.00$ and $9.01 \%$, respectively, for the GCC method, with $10.79 \%$ higher $E_{\mathrm{NS}}, 0.02$ better $E_{\mathrm{WB}}$, and $6.42 \%$ lower PDE than those for Nash method. Overall, the GCC outperformed the Nash IUH model with an average Nash-Sutcliffe efficiency coefficient increased by $7.66 \%$, and an average PDE decreased by $4.14 \%$. The differences in performance between GCC and Nash IUH varied with watershed scale. The averages of improved performance for $E_{\mathrm{NS}}$ were 2.28, 5.34 and $8.62 \%$, respectively, for Dagutai, Bailianhe, and Kaifengyu watersheds in the calibration period, which suggests that the advantage of the GCC method over the Nash IUH increases with the area of the watershed.
The superior performance of the GCC in this case is possibly explained by the three watersheds, all greater than $500 \mathrm{~km}^{2}$ in area, being too large for reliable application of the Nash IUH. The linear reservoir-channel cascade of the GCC method can represent the spatial heterogeneity of these large watersheds, and thus generates a more realistic hydrograph. The 18 storm events examined here varied in terms of rainfall magnitude (indicated by average, maximum and minimum total rainfall volume), and spatial variability of rainfall (indicated by ratio of maximum to minimum rainfall and coefficient of spatial variation) (Table 1). A positive relationship between storm event rainfall spatial variability indicators and improved model goodness-of-fit implied that the higher the spatial variability of rainfall the greater was the performance advantage of the GCC method compared with the Nash method. This explains the observed superior performance of the GCC compared with the Nash IUH as watershed area increased, because for our case studies, the larger watershed area was associated with generally higher storm event rainfall variability. For storm events with spatially homogeneous rainfall across the watershed under consideration, the advantage of the GCC over the Nash IUH method would be diminished. 
The above point can be illustrated by the examples of storm events ID 14 and ID 18 in Kaifengyu watershed. Storm ID 14 was caused by local convective weather which brought high intensity precipitation only to the headwater area. In this case, the calculated coefficient of spatial variation was 1.76 and the maximum rainfall volume was greater than the minimum by a factor of 5.75 (Table 1). The assumption of uniform distribution of precipitation over the entire watershed by Nash IUH led to an earlier rise in the hydrograph. On the other hand, the GCC method divided Kaifengyu watershed into five subareas and routed the uneven effective rainfall separately through the reservoir-channel cascade, which retained the heterogeneous characteristics of the storm. By considering rainfall as a distributed phenomenon, a more realistic rising limb and peak of the flood hydrograph was estimated. In contrast to storm ID 14, storm ID 18 was characterized by relatively uniform precipitation over the watershed, with a low coefficient of spatial variation of 0.33 (Table 1). In this case, the hydrographs generated by the GCC and Nash methods were similar, and both were a realistic representation of the observed hydrograph (Figure 5).

The theory of the GCC was developed to overcome the problem of heterogeneous rainfall distribution that is characteristic of larger watersheds (i.e. area $>500 \mathrm{~km}^{2}$ ). Application of the GCC method to multiple storm events in three watersheds in the subtropical monsoon climate zone of China with heterogeneous rainfall distribution demonstrated its superior performance compared to the traditional Nash method. The robustness and applicability of the GCC method across other physiographic areas requires further investigation. In addition, the work required to divide a large watershed into subareas to consider uneven rainfall distribution can be relatively tedious, although less so for experienced GIS operators. This might be a potential drawback for application of the GCC compared with the simpler traditional UH methods. Thus, the traditional Nash IUH will remain a satisfactory approach for watersheds with rivers of even riverbed slope and homogeneous rainfall distribution.

\section{Sensitivity of UH curves to parameter values}

Analysis of the GCC model sensitivity to varying parameter values was examined for storm ID 14 from the Kaifengyu watershed as an example, an event with high intensity precipitation localized to the headwater area. The $S$ curves and UHs for each subarea were compared to identify parameter behavior. It was found that the further away the subarea was located from the outlet of the watershed, the later was the start time of the $S$ curve, while the nearer the subarea was to the outlet, the earlier the $S$ curve value reached 1 (Figure 6(a)). This was an expected result, because the GCC method considers both water storage and water translation components of each subarea. The integrated $S$ curve (Figure 6(a)) was obtained by multiplying the $S_{i}(t)$ curve and the corresponding area weights of each subarea.

The UH curves (Figure 6(b)) had features similar to those of the $S$ curves (Figure 5(a)), except that the peak values for each UH curve did not follow a monotonic
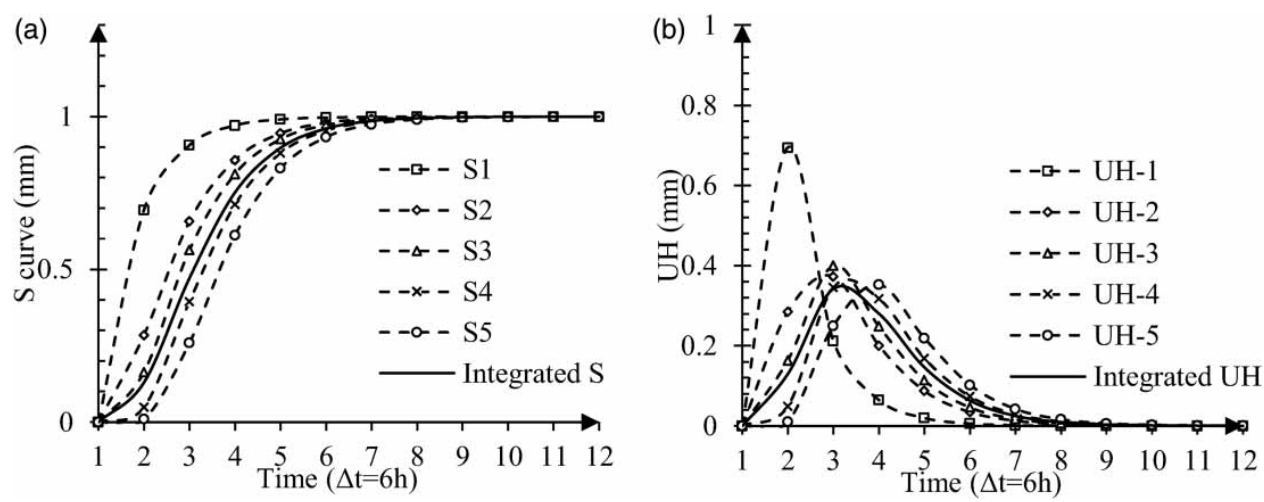

Figure 6 | $S$ curves (a) and UHs (b) for GCC method. 
decreasing trend in the downstream direction. The UH curve for subarea 2 had a lower peak than that for subarea 3 (Figure 6(b)). Also, the difference between the first and second highest values in subarea 2 was small compared with the more peaked UH curves from the other subareas. This resulted from the competing effects of water storage, described by $K$, and water translation, described by $\tau$. Varying $\tau$ with fixed $K$ (Figure 7(a)) demonstrated that a high value of $\tau$ corresponded with a late time to peak, and a low value of $\tau$ corresponded with an early time to peak, while the value of $\tau$ had an indistinct effect on the magnitude of the UH peak. The relationship between $\tau$ and time to peak varied between subareas. Subareas 1 and 2, close to the watershed outlet, had a short channel length, so the translation component was small enough to be ignored. This explains why the Nash IUH, which does not take the channel effect into consideration, performs well in small watersheds less than about $500 \mathrm{~km}^{2}$ in area. Subareas 3, 4 , and 5, which were distant from the watershed outlet, all had a translation component large enough that it could not be ignored. Varying $K$ with fixed $\tau$ (Figure $7(b)$ ) demonstrated that the larger the value of $K$ the smaller was the peak and the later was the time to peak. This is consistent with the physical theory that the larger the water storage capacity (represented by $K$ ), the greater the flood attenuation effect. $K$ had no effect on time to peak in subarea 1 because the first reservoir produced impulse $\mathrm{UH}$, as for the Clark IUH. In this case, the time to peak is deterministic, and destined to be the first moment. For the other subareas, $K$ had an effect on both peak and time to peak.

\section{CONCLUSION}

A new representation of the UH named the GCC method was proposed by combining a simple isochrone method based on riverbed slope with a conceptual cascade of reservoirs and channels. The GCC, which simulates watershed runoff by considering flood attenuation and translation processes, and by progressively concentrating rainfall excess along the river, was devised as a conceptual model with physical meaning. The GCC was tested using data from 18 storm events at a 6-hourly time step from three watersheds located within the Yangtze River Basin, China. The main conclusions drawn from this paper are:

1. The four well-known existing concentration curves of Clark, Kalinin-Milyukov, Nash and Dooge were found to be special cases of the GCC, with different simplifying assumptions. Thus, the GCC is a generalized method that can be applied across a wide range of conditions.

2. The way that rainfall excess is progressively concentrated along the river in the GCC eliminated the assumption of uniform rainfall distribution across the watershed, thus opening the potential to expand application of the UH concept to large watersheds.

3. Application of the GCC method to data from three watersheds in China indicated that both the GCC and the Nash IUH methods simulated storm hydrographs with reasonable accuracy. However, goodness-of-fit statistics suggested that the GCC method outperformed the Nash method, with average Nash-Sutcliffe efficiency coefficient higher by $7.66 \%$, and average PDE lower by 4.14\%. This result appears to be due to the Nash IUH method being less suited to application in watersheds larger than around $500 \mathrm{~km}^{2}$ with heterogeneous rainfall.

4. The water storage coefficient $(K)$ influenced the peak of the UH in subareas close to the watershed outlet, and influenced both peak and time to peak in subareas distant from the outlet. The water translation time $(\tau)$ had no impact on hydrograph characteristics in the subarea closest to the watershed outlet, but it influenced time to peak in subareas distant from the outlet.

5. In modelling storm events for a watershed with even riverbed slope and homogeneous rainfall distribution, compared with a simpler traditional UH, the GCC could mean a larger calculation effort that realizes an insignificant benefit in improved results. For this situation, the traditional Nash IUH will continue to find satisfactory application.

It is noted that, in this paper, the GCC method was verified using data from three watersheds in the subtropical monsoon climate zone of China as a preliminary demonstration of its utility. Further work is required to test the robustness and applicability of the GCC method in other watersheds covering a wider range of morphometries and climates. 
(1a)

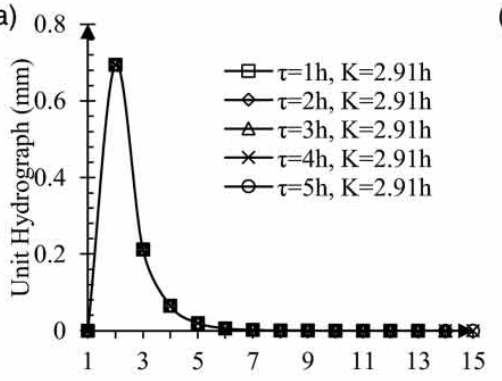

(2a)

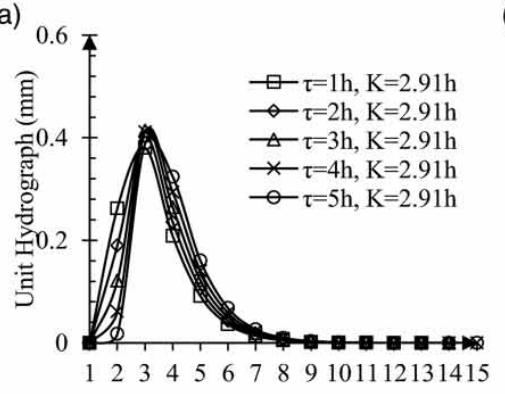

(3a)

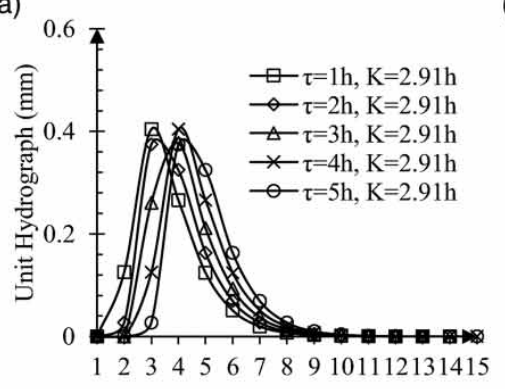

(4a)

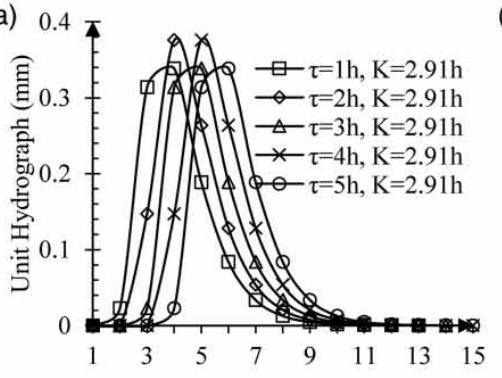

(5a)

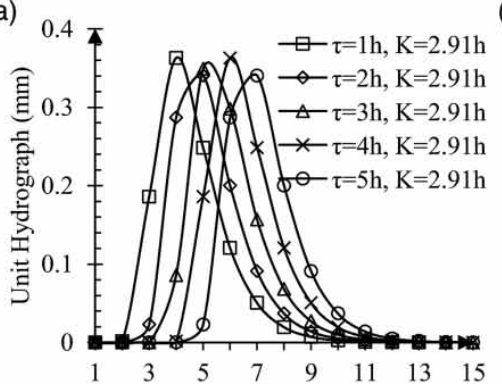

(1b)

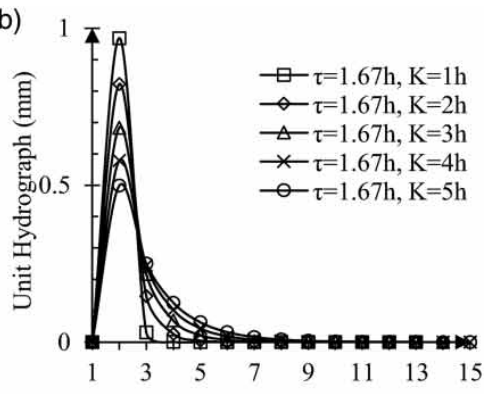

(2b)

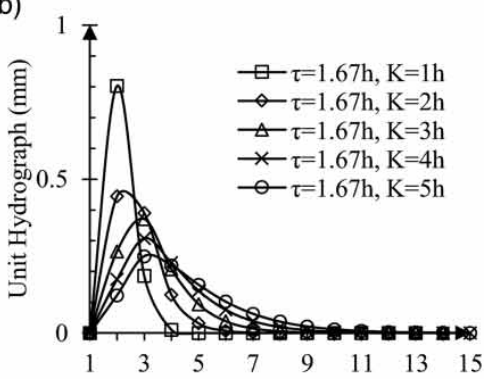

(3b)

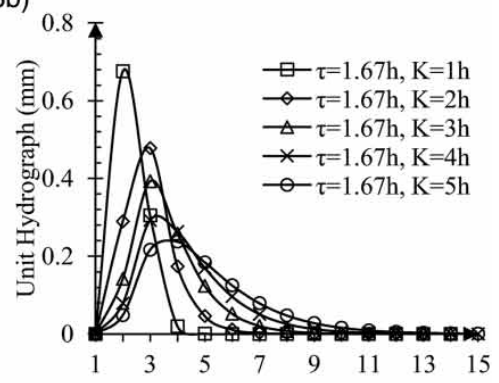

(4b)

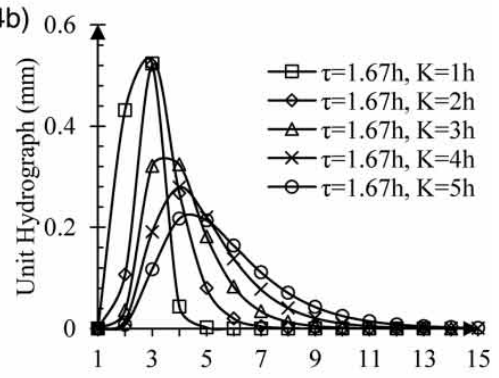

(5b)

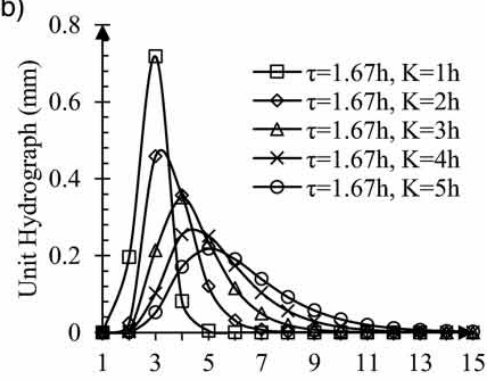

Figure 7 | UHs for the five subareas 1-5 for various combinations of values of parameters $\tau$ and K. Plots labeled $1 \mathrm{a}-5 \mathrm{a}$ are for variable $\tau$ and fixed K, and plots labeled $1 \mathrm{~b}-5 \mathrm{~b}$ are for fixed $\tau$ and variable $\mathrm{K}$. 


\section{ACKNOWLEDGEMENTS}

This study was supported by the National Natural Science Foundation of China (51279139 and 51279140) and National Grand Science and Technology Special Project of Water Pollution Control and Improvement (No. 2014ZX07204006).

\section{REFERENCES}

Beven, K. J. 2oII Rainfall-Runoff Modelling: The Primer. John Wiley \& Sons, New Jersey.

Chow, V. T. I959 Open-Channel Hydraulics. McGraw-Hill, New York

Chow, V. T., Maidment, D. R. \& Mays, L. W. 1988 Applied Hydrology. McGraw-Hill, New York.

Clark, C. O. 1945 Storage and the unit hydrograph. Trans. ASCE 110, 1419-1446.

Dooge, J. C. I. 1957 Discussion [of 'the form of the instantaneous unit hydrograph' (Nash, 1957)]. Int. Assoc. Sci. Hydrol. Publ. 45, 120-121.

Dooge, J. C. I. 1959 A general theory of the unit hydrograph. J. Geophys. Res. 64, 241-256.

Dooge, J. C. I. 1973 Linear Theory of Hydrologic Systems. Agricultural Research Service, US Department of Agriculture, Washington, DC.

Duan, Q., Gupta, V. K. \& Sorooshian, S. I993 Shuffled complex evolution approach for effective and efficient global minimization. J. Optimiz. Theory Appl. 3, 501-521.

Finsen, F., Milzow, C., Smith, R., Berry, P. \& Bauer-Gottwein, P. 2014 Using radar altimetry to update a large-scale hydrological model of the Brahmaputra river basin. Hydrol. Res. 45 (1), 148-164.

Kalinin, G. P. \& Milyukov, P. I. 1957 Oraskete neustanovivshegosya dvizhenia vody v otkrytykh ruslakh (On the computation of unsteady flow in open channels). Metrologiya i gidologiya zhuzurnal 10, 10-18 (in Russian).

Kang, K. \& Merwade, V. 2014 The effect of spatially uniform and non-uniform precipitation bias correction methods on improving NEXRAD rainfall accuracy for distributed hydrologic modeling. Hydrol. Res. 45, 23-42.

Li, C. Q., Guo, S. L., Zhang, W. H. \& Zhang, J. 2008 Use of Nash's IUH and DEMs to identify the parameters of an unequalreservoir cascade IUH model. Hydrol. Process. 22, 4073-4082.

Li, H., Beldring, S. \& Xu, C. Y. 20I4 Implementation and testing of routing algorithms in the distributed Hydrologiska Byråns Vattenbalansavdelning model for mountainous catchments. Hydrol. Res. 45, 322-333.

Lin, K. R., Guo, S. L., Zhang, W. H. \& Liu, P. 2007 A new baseflow separation method based on analytical solutions of the Horton infiltration capacity curve. Hydrol. Process. 21, 1719-1736.
Moon, J., Srinivasan, R. \& Jacobs, J. H. 2004 Stream flow estimation using spatially distributed rainfall in the Trinity River basin, Texas. Trans. ASAE 47, 1445-1451.

Nash, J. E. 1957 The form of the instantaneous unit hydrograph. Int. Assoc. Sci. Hydrol. Publ. 45, 114-119.

Nash, J. E. I960 A unit hydrograph study with particular reference to British catchments. ICE Proc. 17, 249-282.

Nash, J. E. \& Sutcliffe, J. 1970 River flow forecasting through conceptual models. J. Hydrol. 10, 282-290.

O'Kelly, J. J. 1955 The employment of unit-hydrographs to determine the flow of Irish arterial drainage channels. ICE Proc. 4, 365-412.

Ramirez, J. A. 2000 Predictions and modeling of flood hydrology and hydraulics, Chapter 11. In: Inland Flood Hazards: Human Riparian and Aquatic Communities. (E. Wohl, ed). Cambridge University Press, Cambridge.

Razavi, T. \& Coulibaly, P. 2012 Streamflow prediction in ungauged basins: review of regionalization methods. J. Hydrol. Eng. 18, 958-975.

Rodriguez-Iturbe, I. \& Valdés, J. B. I979 The geomorphologic structure of hydrologic response. Water Resour. Res. 15, 1409-1420.

Ross, C. N. I92I The calculation of flood discharges by the use of a time-contour plan. Trans. Inst. Eng. Aus. 2, 85-92.

Shaw, E. M. 1994 Hydrology in Practice, 3rd edn. Taylor \& Francis, London.

Sheridan, J. M. 1994 Hydrograph time parameters for flatland watersheds. Trans. ASAE 37, 103-113.

Sherman, L. K. 1932 Streamflow from rainfall by the unit-graph method. Eng. News Record 108, 501-505.

Singh, V. P. 199o Hydrologic System Rainfall-Runoff Modelling. Prentice Hall, Englewood Cliffs, New Jersey.

Singh, V. P. 20II An IUH equation based on entropy theory. Trans. $A S A B E$ 54, 131-140.

Sittner, W. T., Schauss, C. E. \& Monro, J. C. 1969 Continuous hydrograph synthesis with an API-type hydrologic model. Water Resour. Res. 5, 1007-1022.

Todini, E. 2007 Hydrological catchment modelling. Hydrol. Earth Syst. Sci. 11, 468-482.

Wang, Q. L. I982 The instantaneous concentration model considering time lag. J. China Hydrol. 1, 13-19 (in Chinese).

Wu, S.-J., Lien, H.-C., Hsu, C.-T., Chang, C.-H. \& Shen, J.-C. 2015 Modeling probabilistic radar rainfall estimation at ungauged locations based on spatiotemporal errors which correspond to gauged data. Hydrol. Res. 46 (1), 39-59.

Xu, H., Xu, C. Y., Chen, H., Zhang, Z. \& Li, L. 2013 Assessing the influence of rain gauge density and distribution on hydrological model performance in a humid region of China. J. Hydrol. 505, $1-12$.

Yang, Z. \& Han, D. 2006 Derivation of unit hydrograph using a transfer function approach. Water Resour. Res. 42, W01501.

Zhang, J. Y. 20I0 Review and reflection on China's hydrological forecasting techniques. Adv. Water Sci. 21, 435-443 (in Chinese with English abstract). 
Zhang, W. H., Zhang, L. P., Xia, J. \& Zhang, X. 20Io Using the gradient of river bed to plot isochronal lines of watersheds. J. China Hydrol. 30, 1-5 (in Chinese with English abstract).

Zoch, R. R. I934 On the relation between rainfall and streamflow. U.S. Dept. of Commerce, Monthly Weather Review, Part I 62 315-322.
Zoch, R. R. 1936 On the relation between rainfall and streamflow. U.S. Dept. of Commerce, Monthly Weather Review, Part II 64, 105-121.

Zoch, R. R. 1937 On the relation between rainfall and streamflow. U.S. Dept. of Commerce, 20 Monthly Weather Review, Part III 65, 135-147.

First received 30 March 2015; accepted in revised form 28 August 2015. Available online 23 October 2015 